\title{
Headache in an emergency room in Brazil
}

\author{
Department of N eurology, São Paulo U niversity, \\ School of M edicine at Ribeirão Preto, Riberao Preto, B razil
}

\begin{abstract}
CONTEXT: $W$ hen experiencing a headache attack, Brazilian patients usually look for a primary care service, where they are seen by general clinicians. In the town of Ribeirão Preto, these clinicians routinely refer patients to the Emergency Room of the University Hospital.

OBJ ECTIVE: The objective of this study was to evalua te the quality of primary care by analyzing retrospectively the medical records of patients with a complaint of headache seen in this emergency room during the year of 1996.

DESIGN : retrospective study.

SETmING: Emergency Room of the Universital Hospital, Ribeirão Preto, São Paulo, reference unit.

PARTICIPANTS: 1254 patients. The patients who sought the Emergency Room (ER) of the University Hospital of Ribeirão Preto, during the year of 1996 with a complaint of headache were studied retrospectively.
\end{abstract}

MAIN MEASUREMENTS: Etiology, age, diagnosis, secondary cause, laboratory tests.

RESULTS: Of the 1254 patients seen (61\% women), 1190 (94.9\%) were discharged after the administration of parenteral analgesics before they had spent 12 hours in the room. 0 nly 64 (5.1\%) patients remained for more than 12 hours. Of the patients who spent less than 12 hours in the room, $71.5 \%$ had migraine or tension type headache and did not require subsidiary exams for diagnosis. of the patients who spent more than 12 hours in the room, $70.3 \%$ had secondary headaches.

CONCLUSIONS: We conclude the primary care for headache is unsatisfactory in the Ribeirão Preto region. Many patients with primary headache are referred to tertiary care services, indicating the need for the dissemination of the diagnostic criteria of the International Headache Society to general practitioners.

KEY WORDS: Headache. G eneral practioners. Emergency room.

\section{INTRODUCTION}

Headache is one the symptoms most frequently reported in doctors' offices, involving considerable economic losses, as well as an important worsening of the quality of life of those who suffer from it. ${ }^{1}$ It is the most frequent cause of adult worker absenteeism in the United States. ${ }^{2,3}$ Despite its high incidence, headache has been little studied in Brazil. We have no data about the percentage of Brazilians who look for medical care either during an attack or between attacks. As is al so the case for other countries, self-medication or looking for a pharmacy clerk is common during the acute phase. ${ }^{4}$

An undetermined percentage of persons with headache looks for primary care provided by general practitioners in primary care units. The cases of acute headache seen at these units which are refractory to treatment or raise doubts about their primary etiology are referred to more differentiated care units. ${ }^{5,6}$ This is also a routine occurrence in the town of Ribeirão Preto, where the present study was conducted.

In the present investigation we studied retrospectively the patients with a complaint of headache who sought the Emergecy Room of the University Hospital of Ribeirão Preto, a tertiary care unit, in the year of 1996, with the objective of evaluating the quality of primary care for acute headaches.

\section{METHODS}

The patients who sought the Emergency Room (ER) of the University Hospital of Ribeirão Preto, dur- 
ing the year of 1996 with a complaint of headache were studied retrospectively. Since the hospital is a reference unit it receives patients from an extensive region which includes not only the municipality (population of approximately 450,000), but also towns located more than 200 km from Ribeirão Preto. Patients seen at primary health care units are referred to this unit when they are refractory to treatment or when doubts exist about the primary etiology of their complaint. As they arrive at the $E R$, the patients are seen by the Neurology team which consists of three residents and a supervisor with specialization in Neurology. A detailed clinical-neurological examination is performed and the patients receive parenteral analgesics or antiinflammatory agents.

A total of 1254 patients arrived at the ER with a complaint of headache in the year of 1996. Of these, 1190 were discharged before 12 hours of permanence on the basis of a significant improvement or absence of headache and of normal clinical-neurological and subsidiary exams. The patients who spend more than 12 hours in the observation rooms are considered to have been hospitalized by the statistics service of the hospital.

The present series consists of a random sample of 165 non-hospitalized patients and of all the hospitalized patients ( $\mathrm{N}=64$ ).

Headache was classified into 3 groups according to etiology: 1) primary headache (with the pain episode fulfilling IHS7 criteria for primary headache), 2) headache secondary to neurological disorders, and 3) headache secondary to systemic disorders. The patients were then studied in terms of clinical and epidemiological aspects and submitted to laboratory tests.

\section{RESULTS}

In 1996, 1254 patients were referred to the ER with a complaint of headache. Of these, 769 were women (61\%) and 485 were men (39\%). Most patients (94.9\%) spent less than 12 hours in the ER. Only 64 patients (5.1\%) were hospitalized, i.e., they spent more than 12 hours in the hospital environment. Patient distribution by age is given in Table 1.

About $80 \%$ of patients were less than 40 years old. The proportion of hospitalized patients was higher among subjects either younger than 10 years or older than 50 years. The age range that least required hospitalization was $40-50$ years. Table 2 shows the etiologies of the headaches presented by the patients of the present series.

Primary headaches predominated among non- hospitalized patients (77.0\%), whereas the percentage of headaches secondary to neurological disorders was higher among patients who required hospitalization (51.5\%). However, this proportion varied widely with age range, as shown in Figure 1.

The various types of primary headaches detected in the present series of patients, according to the IHS classification, are listed in Table 3. It can be seen that $77 \%$ of the non-hospitalized patients (Table 2 ) had primary headache, with $56.4 \%$ of the total presenting migraine (Table 3). If we add this value to that obtained for tension headache (15.1\%), we can see that $71.5 \%$ of the patients seen in the ER of a tertiary care unitt did not require hospitalization and presented migraine

Table 1 - Distribution by age of non-hospitalized and hospitalized patients

\begin{tabular}{lrr}
\hline Age(years) & Total group of patients & Hospitalized Patients \\
\hline $0-9$ & $127(10.1)$ & $14(21.9)$ \\
$10-19$ & $251(20.0)$ & $11(17.2)$ \\
$20-29$ & $391(31.2)$ & $12(18.8)$ \\
$30-39$ & $231(18.4)$ & $8(12.5)$ \\
$40-49$ & $144(11.5)$ & $7(10.9)$ \\
50 and more & $110(8.8)$ & $12(18.7)$ \\
\hline Total & $\mathbf{1 2 5 4}(\mathbf{1 0 0})$ & $\mathbf{6 4}(\mathbf{1 0 0})$ \\
\hline
\end{tabular}

$\%$ given in parenthesis

Table 2 - Distribution by etiology of the headaches presented by non-hospitalizedand hospitalized patients

\begin{tabular}{lcc} 
& Non-hospitalized & Hospitalized \\
\hline $\begin{array}{l}\text { Primary headache } \\
\text { Headache secondary to }\end{array}$ & $127(77.0)$ & $19(29.7)$ \\
$\begin{array}{l}\text { neurological disorders } \\
\text { Headache secondary to }\end{array}$ & $15(9.1)$ & $33(51.5)$ \\
systemic disorders & $23(13.9)$ & $12(18.8)$ \\
\hline Total & $\mathbf{1 6 5 ( 1 0 0 )}$ & $\mathbf{6 4}(\mathbf{1 0 0 )}$ \\
\hline
\end{tabular}

* Random samples, ** Total number of hospitalized patients; \% given in parenthesis.

Table 3 - Primary headaches diagnosed in hospitalized and non-hospitalized patients

\begin{tabular}{lrrr} 
& Non-hospitalized & Hospitalized \\
\hline M igraine & $93(56.4)$ & $14(21.9)$ \\
M igraine without aura & $62(37.6)$ & $8(12.5)$ \\
M igraine with aura & $27(16.3)$ & $5(7.8)$ \\
$\quad$ Typical aura & $23(13.9)$ & $3(4.7)$ \\
Basilar & $4(2.4)$ & $2(3.1)$ \\
Migraine complications & $4(2.4)$ & $1(1.6)$ \\
$\quad 3$ Status migranosus & $3(1.8)$ & 1 & $(1.6)$ \\
Migraine infarction & $1(0.6)$ & $0(0)$ \\
Tension-type & $25(15.1)$ & $2(3.1)$ \\
Cervicogenic & $2(1.2)$ & $1(1.6)$ \\
N euralgia & $1(0.6)$ & $0(0)$ \\
Chronic daily & $2(1.2)$ & $0(0)$ \\
Conversive & $3(1.8)$ & $2(3.1)$ \\
Benign, due to effort & $1(0.6)$ & $0(0)$ \\
\hline Total & $\mathbf{1 2 7}(\mathbf{7 7 . 0})$ & $\mathbf{1 9}(\mathbf{2 9 . 7 )}$ \\
\hline
\end{tabular}

$\%$ given in parenthesis 
or tension-type headache.

The etiologies of the headaches secondary to neurological disorders are presented in Table 4. These headaches corresponded to less than $10 \%$ of the cases of headache that did not require patient hospitalization and even in these cases the etiology was relatively benign (Table 4). Of the hospitalized patients, 51.5\% had headaches secondary to neurological disorders.

Table 4 - Causes of headache secondary to neurological disorders among non-hospitalized and hospitalized patients

\begin{tabular}{lcrl}
\hline & Non-hospitalized & Hospitalized \\
\hline Pseudotumor cerebri & $0(0)$ & $2(3.1)$ \\
M alfunctioning VPS & $0(0)$ & $2(3.1)$ \\
M eningitis & $0(0)$ & 4 & $(6.2)$ \\
N eoplasia & $0(0)$ & 1 & $(1.6)$ \\
G ranuloma & $0(0)$ & 2 & $(3.1)$ \\
Acute post-traumatic & $5(3.0)$ & 5 & $(7.8)$ \\
Postconvulsion & $2(1.2)$ & $3(4.7)$ \\
Post-spinal tap & $4(2.4)$ & 2 & $(3.1)$ \\
Stroke & $0(0)$ & 4 & $(6.2)$ \\
O titis & $2(1.2)$ & 0 & $(0)$ \\
Subdural hematoma & $0(0)$ & $3(4.7)$ \\
Subarachnoid hemorrhage & $0(0)$ & 1 & $(1.6)$ \\
Glaucoma & $1(0.6)$ & 1 & $(1.6)$ \\
Hydrochephaly & $1(0.6)$ & 1 & $(1.6)$ \\
Arteritis & $0(0)$ & 1 & $(1.6)$ \\
Hygroma & $0(0)$ & 1 & $(1.6)$ \\
\hline Total & $\mathbf{1 5}(\mathbf{9 . 1 )}$ & $\mathbf{3 3}(\mathbf{5 1 . 5 )}$ \\
\hline
\end{tabular}

VPS = Ventriculoperitoneal shunt; \% given in parenthesis

Table 5 - Causes of headaches secondary to systemic disorders among non-hospitalized and hospitalized patients

\begin{tabular}{lcc}
\hline & Non-hospitalized & Hospitalized \\
\hline Sinusitis & $8(4.8)$ & $5(7.8)$ \\
Systemic infection & $6(3.6)$ & $5(7.8)$ \\
Drug abuse & $4(2.4)$ & $0(0)$ \\
Arterial hypertension & $2(1.2)$ & $0(0)$ \\
SHDP & $0(0)$ & $2(3.1)$ \\
Postural hypotension & $2(1.2)$ & $0(0)$ \\
Hypoglycemia & $1(0.6)$ & $0(0)$ \\
\hline Total & $\mathbf{2 3}(\mathbf{1 7 . 6 )}$ & $\mathbf{1 2}(\mathbf{1 8 . 8 )}$ \\
\hline
\end{tabular}

SHDP = Specific hypertensive disease of pregnancy; \% given in parenthesis.

Table 6 - Laboratory tests requested

\begin{tabular}{lcc}
\hline & Non-hospitalized & Hospitalized \\
\hline Blood tests & $8(4.8)$ & $27(42.2)$ \\
Skull/ face radiography & $21(12.7)$ & $16(25.0)$ \\
Computer tomography & $15(9.1)$ & $33(51.6)$ \\
Spinal tap & $2(1.2)$ & $25(39.0)$ \\
N uclear magnetic resonance & $0(0)$ & $3(4.7)$ \\
Encephalic panangiography & $0(0)$ & $4(6.2)$ \\
Carotid ultrasound & $0(0)$ & $2(3.1)$ \\
Electroencephalogram & $1(0.6)$ & $4(6.2)$ \\
O thers & $0(0)$ & $1(1.6)$ \\
\hline Total number of patients & $\mathbf{2 9 ( 1 7 . 6 )}$ & $\mathbf{4 8 ( 7 5 . 0 )}$ \\
\hline
\end{tabular}

$\%$ given in parenthesis.
Headaches secondary to systemic disorders were diagnosed in $13.9 \%$ of non-hospitalized patients and in $18.7 \%$ of hospitalized patients. The causes detected are listed in Table 5.

The laboratory tests requested are listed in Table 6 . Since the ER is not equipped with a magnetic resonance apparatus, patients who require the exam must be referred to the University Hospital on the University Campus, located about $10 \mathrm{~km}$ from the ER. Blood tests included blood counts, serology, biochemistry and all remaining procedures.

It can be seen that for non-hospitalized patients the diagnosis was eminently clinical. The exam most frequently requested was a skull and/or face $X$-ray. Less than $10 \%$ of patients were submitted to computer tomography and only $1.2 \%$ were submitted to spinal taps. In contrast, $75 \%$ of hospitalized patients were submitted to exams, $56.3 \%$ to computer tomography or nuclear magnetic resonance and $39 \%$ to spinal taps.

\section{DISCUSSION}

Several studies have reported the high incidence of headache in the population and in health services. ${ }^{8-16}$ Data obtained by one of us (M.E.B.) have shown that from 6006 patients were seen at two primary care units in Brazil over a period of 8 months, headache accounted for $9,3 \%$ of unscheduled visits, i.e., visits due to acute problems. ${ }^{17}$ General practitioners examine these patients and, when they deem it necessary they refer the patients to more differentiated health care units. The major tertiary care unit in Ribeirão Preto is the $E R$, where 1254 patients were seen in 1996.

Approximately $80 \%$ of the patients seen in the ER were younger than 40 years, indicating a lower incidence of headache among older people. Age and sex distribution show a predominance of headache among

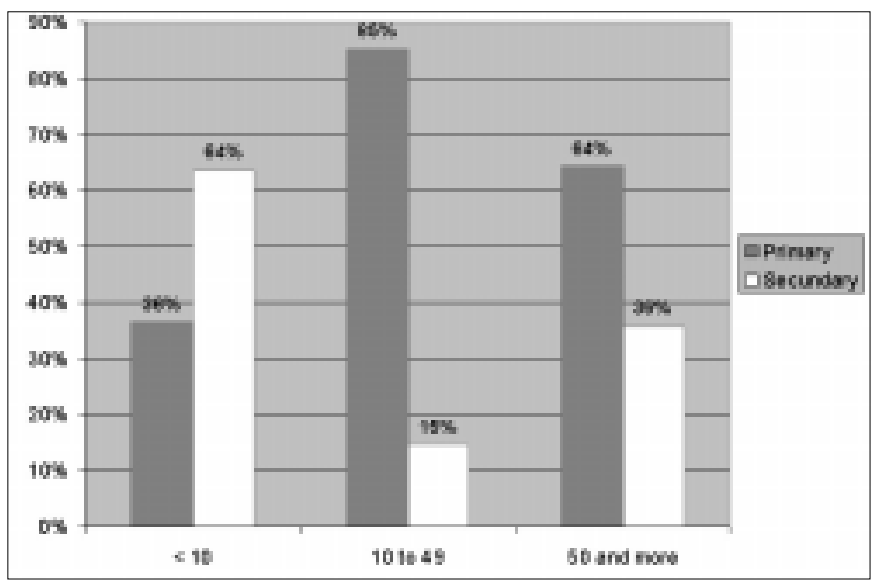

Figure 1 - Etiologies of the headaches according to age range among non-hospitalized patients. 
women and in younger ages. A larger number of hospitalizations was indicated for patients younger than 10 or older than 50 years. A greater percentage of headaches secondary to systemic disorders was observed in these age ranges. These findings are similar to those found by others. $2,9-12,16-18$

A complete work-up was performed on $17.6 \%$ of non-hospitalized patients and on $75 \%$ of hospitalized patients. Among non-hospitalized patients, 77\% received a diagnosis of primary headache and among the hospitalized ones $70.3 \%$ received a diagnosis of secondary headache (Table 2). These data suggest that when the pain persists after several hours and after the administration of analgesics, neurological exams should be repeated and specialized tests such as CT scans, magnetic nuclear resonance and/or spinal tap should be carried over since there is an increased possibility of the presence of secondary headache. Moreover, these data might serve as the basis for an organized clinical reasoning at a time of cost rationalization.

In the evaluation of the medical performance of general clinicians at primary health care centers two facts were particular outstanding: 1) a small number $(5.1 \%)$ of the patients referred to the $E R$ required hospitalization, and 2) $71.5 \%$ of these patients had primary headaches that responded well to symptomatic treatment of the pain and were discharged after this procedure. This being a tertiary care unit, a higher percentage of secondary headaches was expected to be diagnosed.

The above data, taken as a whole, show that most of the patients with primary headaches were young and did not require complementary tests, i.e., they presented disorders that could have been resolved at the primary care units. Referral of patients with benign disease to a tertiary care unit raises concerns about costs and efficiency, a much debated topic in developed countries. In developing countries this fact acquires even greater importance because of the lower structuring of the health system, the precarious state investments and the low economic level of the underprivileged population. The system is insufficient to guarantee quality care in view of the high demand. When a patient is improperly referred, costly and unnecessary consequences occur: mobilization of transport with a specialized vehicle and personnel (ambulance), the hospital receiving the patient often works under conditions of overcrowding, with aggravation of the lack of beds and physicians for more serious cases. Improper referral causes a greater delay in the resolution of the problem, with a consequent prolongation of patient suffering and separation from his work, his family or his well-deserved rest. In addition, operational costs are greatly increased.

\section{CONCLUSIONS}

We conclude that the resolution power of the primary health care system in the Ribeirão Preto region in terms of the headache symptom is very low. It should be pointed out that this region is considered to be one of the best medical centers by Brazilian doctors. Thus, it can be seen that headache, as well as precordial pain, frightens general practitioners, generating insecurity among non-specialists, with consequent diagnostic difficulties. However, in contrast to precordial pain, well-established criteria (IHS) are available for headache and in most cases a diagnosis can be made without the use of laboratory tests. Thus, there is a pressing need for a more aggressive dissemination of the diagnostic criteria of the HIS, which would lead to more space for more serious cases in tertiary care units, with decreased operational and individual costs.

\section{REFERENCES}

1. The Migraine Disability and Optimizing Care (MIDAS). A poster presentation. Edited and Sponsored by Zeneca Pharmaceuticals; 1997.

2. National Migraine Foundation. Newsletter; 1995:55.

3. Stang PE, Osterhaus JT. Impact of migraine in the Roomed States: data from the National Health Interview Survey. Headache1993;33:29-35.

4. Carvalho JJF. O balconista de farmácia e o uso de medicação não prescrita em cefaléia: um estudo transversal em Fortaleza. Poster presented in the Headache Session (0077). Curitiba: XVII Brazilian Congress of Neurology; 1996.

5. Zukerman E, Lima JGC, Hannuch, SMM, Carvalho DSC. Unidade de atendimento de agudos com cefaléia (UACC). Rev Ass Med Brasil 1989;35:107-10.
6. Olesen J, Aebelholt A, Veilis, B. The Copenhagen acute headache clinic: organization, patient material and treatment results. Headache 1978;19:223-7.

7. Headache Classification Committee of the International Headache Society. Classification of headache disorders, cranial neuralgias and facial pain. Cephalalgia 1988;8(suppl 7):1-9.

8. Henry P, Michel P, Brochet P, Dartigues JF, Tison S, Salamon R. GRIM, a nationwide survey of migraine in France: prevalence and clinical features in adults. Cephalalgia 1992;12:229-37.

9. Lavados PM, Tenhamm E. Epidemiology of migraine headache in Santiago, Chile: a prevalence study. Cephalalgia 1997;17:770-7.

10. Lipton RB, Stewart, WF. Epidemiology and comorbility of migraine. In 
Goadsby PJ, Silberstein SD, editors. Headache. Boston: ButterworthHeinemann; 1997:75-95.

11. Lipton RB, Silberstein MD, Stewart WF. An update on the epidemiology of Migraine. Headache 1994;34:319-28.

12. Abu-Arefeh I, Russel, G. Prevalence of headache and migraine in schoolchildren. Br Med J 1994;309:765-9.

13. Arruda MA. Aspectos diagnósticos da cefaléia na infância. In: Anais do XII Congresso da Sociedade Brasileira de Cefaléia, Brasil; 1998.

14. Barea LM, Tanhouser M, Rotta NT. An epidemiologic study of headache among children and adolescents of southern Brazil. Cephalalgia
1996;16:545-9.

15. Bille B. Migraine in school children. Acta Paediatr Scand 1992;51(Suppl 136):1-151.

16. Leicht MJ. Non-traumatic headache in the emergency department. Ann Emerg Med 1980;9:404-9.

17. Bigal ME, Bordini CA, Speciali JG. Etiology and distribution of headaches in two Brazilian primary care units. Headache, in press.

18. Welch KMA. Headache in the Emergency Room. In: Olesen P, TfeltHansen, Welch KMA, eds. The headaches. New York: Raven Press; 1993:23-42.

\section{resumo}

CONTEXTO: Q uando em crise de cefaléia, pacientes brasileiros geralmente dirigem-se a uma unidade básica de saúde, onde são atendidos por clínicos gerais. $\mathrm{N}$ a cidade de Ribeirão Preto, os clínicos rotineiramente referem os pacientes para a Unidade de Emergência (UE) do Hospital das Clínicas.

OBJETVO: Avaliar a qualidade do serviço primário, analisando retrospectivamente o prontuário de pacientes que procuraram a EU, no ano de 1996, com queixa de cefaléia.

TIPO DE ESTUDO: Estudo retrospectivo.

LOCAL: Unidade de Emergência do Hospital das Clínicas da Faculdade de Medicina de Ribeirão Preto.

PARTICIPANTES: 1.254 pacientes. O $s$ pacientes da Unidade de Emergência do hospital da Universidade de Ribeirão Preto durante o ano de 1996 com crise de cefaléia foram estudados retrospectivamente.

VARIÁVEIS ESTUDADAS: Etiologia, idade, diagnóstico, causa secundária e testes laboratoriais.

RESULTADOS: Dos 1254 pacientes vistos (61\% mulheres), 1190 $(94,9 \%)$ tiveram alta, a pós a administração de analgésicos parenterais, com menos de 12 horas da admissão. A penas 64 pacientes $(5,1 \%)$ permaneceram mais de 12 horas. Dos que ficaram menos de 12 horas, $71,5 \%$ apresentavam migrânea ou cefaléia tipo tensional e não necessitaram exames subsidiários. Dos que permaneceram mais de 12 horas, 70,3\% apresentavam cefaléias secundárias.

CONCLUSÃO: Concluímos que o serviço primário é ineficaz, para a cefaléia, na região de Ribeirão Preto. Muitos pacientes com cefaléia primária são referidos para centros terciários, indicando a necessidade urgente da divulgação dos critérios diagnósticos da Sociedade Internacional de Cefaléia para clínicos gerais.

PALAVRAS-ChAVE: Cefaléia. Clínicos gerais. Unidade de emergência.

\section{publishing information}

Marcelo Eduardo Bigal, MD. Department of Neurology, São Paulo University, School of Medicine at Ribeirão Preto, Ribeirao Preto, Brazil.

Carlos Alberto Bordini, PhD. Department of Neurology, São Paulo University, School of Medicine at Ribeirão Preto, Ribeirao Preto, Brazil.

José Geraldo Speciali, PhD. Department of Neurology, São Paulo University, School of Medicine at Ribeirão Preto, Ribeirao Preto, Brazil.

Sources of funding: Not declared

Conflict of interest: Not declared

Last received: 15 February 2000

Accepted: 02 March 2000

\section{Address for correspondence:}

José Geraldo Speciali

Departamento de Neurologia, Escola de Medicina de Ribeirão Preto

Universidade de Sao Paulo

Av. Bandeirantes, 3900

Ribeirão Preto/SP - Brasil - CEP 14049-900

E-mail: speciali@netsite.com.br

E-mail: marcelobigal@wac.com.br 